\title{
sciendo
}

\section{How to Win the Basketball Euroleague? Game Performance Determining Sports Results During 2003-2016 Matches}

\author{
by \\ Kazimierz Mikołajec ${ }^{1}$, Damian Banyśs ${ }^{1}$ Justyna Żurowska-Cegielska1, \\ Marek Zawartka ${ }^{3}$, Karol Gryko
}

\begin{abstract}
The main aim of this study was to establish game-related statistics that determined sport results in the Basketball EuroLeague between 2003 and 2016. The study encompasses matches played by 10 teams during 13 consecutive seasons of the EuroLeague. Twenty-two offensive and defensive game related variables were registered. Calculations were performed to establish which of the variables determined performance in the Basketball EuroLeague matches within the analysed period. Based on a number of mathematical and statistical analyses, the elements of play that had the highest effect on sports success were selected. The following determinants displayed the most significant correlations with sport results in the EuroLeague within the analysed period: two-point shots made (2PT-made), twopoint shot attempts (2PT-attempts), three-point shots made (3PT-made), one-point shots made (1PT-made), one-point shot attempts (1PT-attempts), assists, fouls and field goals made. The game outcome in basketball is influenced by many variables which may not always be significant in a given match. However, the continuous effort to maintain these variables at the highest possible level is advantageous over less-organised teams.
\end{abstract}

Key words: game analysis; Euro League; performance indicators; regression model; optimization.

\section{Introduction}

Statistical data concerning the course of a sports match is a very desirable source of information for coaches, athletes and researchers that can be used to evaluate various aspects of performance and the structure of play (Gomes et al., 2017; Mikołajec et al., 2013). The first publications concerning this subject appeared in 1970s (Csataljay et al., 2009). Statistical analyses allow coaches to evaluate the effectiveness of individual, group and team play. Identification of the strong and weak points of a team or an athlete, as well as the elements that need improvement, is the key to permanent progress in performance (Esteves et al., 2020; Gryko et al., 2018). Likewise, the coaches analyse statistics of the opposing teams and choose appropriate tactics, taking into account the opponent's weaknesses and strengths to ensure their team's victory. The combination of performance variables selected for analysis indicates that certain aspects have an important impact on the results of competition (Keele and Kelly, 2006). They constitute a starting point in preparing a game strategy and allow for individual and team assessments (Gryko et al., 2020; Robertson et al., 2016).

Consequently, almost every activity during sports play may be expressed in numbers. Technological developments have allowed for a more precise recording of tactical and technical actions, to obtain essential information about training and managing a team with a high level of performance (Sampaio et al., 2010). Furthermore,

1 - Department of Team Sport Games, Jerzy Kukuczka Academy of Physical Education, Katowice, Poland.

2 - Department of Sport Games, Józef Pitsudski University of Physical Education, Warsaw, Poland.

3 - Institute of Enterpreneurship, Jagiellonian University, Kraków, Poland. 
scientists compare performance in various time periods, individual matches, the regular season, playoffs, a full season or during several seasons (Hughes and Bartlett, 2002) and according to a given aspect of play, e.g. offence or defence (Marmarions et al., 2016; Sampaio et al., 2016). Performance indicators are often used to determine differences between the winning and the losing team (Csataljay et al., 2009; Ibáñez et al., 2008, 2009; Lago-Peñas et al., 2010; Ortega et al., 2006; Parejo et al., 2013; Sampaio and Janeira, 2003). In order to improve their teams' performance, coaches have to determine which factors most differentiate a successful team from an unsuccessful team in both, the Euroleague (Özmen, 2016) and the NBA (Dehesa et al., 2019).

In the study by Çene (2018) which considered Euroleague teams in the 2016-2017 season it was confirmed that two-point field goals made, three-point field goals made, steals and defensive rebounds were crucial for balanced games, as well as two-point field goals made and defensive rebounds were the most influential game statistics on the game outcome for unbalanced games.

Other authors (Paulauskas et al., 2018) suggest that European NBA players outperform their Euroleague peers in two-point field goals made and missed, free-throws made, defensive rebounds, blocks and committed fouls. However, no differences were found in assists, turnovers and steals.

An increasing interest in studies of this type can be observed in recent years. As a result, numerous publications have appeared in which the structure of play and the factors that determine sport results in basketball are analysed. These publications primarily discuss the specifics of play at different positions. An example is a study by Lorenzo et al. (2010), which determined the factors that affected performance of youth teams during the Men's U-16 European Championships (unbalanced games-successful two-point field goals; close games-winning teams had better values in turnovers and assists; balanced games-winning and losing teams were discriminated by successful two-point field goals and defensive rebounds). Parejo et al. (2013) investigated the most significant elements differentiating between the best and the worst teams in the Spanish amateur league regarding balanced games, which were two-points missed shots, scored free-throw shots, defensive rebounds, assists, personal fouls, while in unbalanced games: made field goals, turnovers and blocked shots. Additionally, Mikołajec et al. (2013) carried out a study on the most significant factors determining success in the NBA league in more than 10 consecutive seasons. It was determined that the most critical indicators were the percentage of wins during the whole season, offensive efficiency, the average number of points in the 3rd quarter, the percentage of wins in close games, the average number of fouls and the average number of steals (Mikołajec et al., 2013).

Mandić et al. (2019) conducted a study comparing NBA and EuroLeague statistics. There were no differences in assists, steals, or total rebounds, while differences in two-point, threepoint shooting patterns were non-significant. On the other hand, the number of blocks and a defensive rebounding rate were substantially higher in the NBA. There were more personal fouls per possession in the Euroleague (Mandić et al., 2019).

The main aim of this study was to establish team game-related statistics that determined sport results in the Basketball EuroLeague between 2003 and 2016. Game analysis includes one of the most relevant diagnostic tools in team sports and its results can significantly affect the planning and execution of a training process (Fernandez et al., 2009). If a player or team fails to meet the effectiveness criteria and performs the tactical tasks poorly, it is the coach's duty to determine the cause and choose appropriate methods of training that will change the unfavourable situation (Côté and Gilbert, 2009; Doğan and Ersöz, 2019). Unfortunately, the number of investigations conducted on top-level competition is limited. Therefore, the aim of the present study seems to be justified.

\section{Methods}

\section{Participants}

The research material comprised a set of 21 variables describing the efficiency of play among EuroLeague teams. The source of the data was game variables from the publicly available euroleague.net website. In total, performance of 10 EuroLeague teams over 13 seasons between 
2003 and 2016 was analysed. The research process used data pertaining to the following teams: CSKA Moscow (Russia), FC Barcelona (Spain), Olympiacos Piraeus (Greece), Maccabi Tel Aviv (Israel), Panathinaikos Athens (Greece), Efes Pilsen Istanbul (Turkey), Tau Ceràmica Vitoria (Spain), Unicaja Malaga (Spain), Zalgiris Kaunas (Lithuania) and Partizan Belgrade (Serbia).

Measures

The inclusion criterion for the study group was a given team's participation in EuroLeague games in all seasons of the considered period. The dependent variable was a team's ranking achieved in a given year. The time period was used as the independent variable in some analysis. In the study, sport results from 2003-2016 obtained by the teams during the regular season were analysed. Next, in accordance with the objectives of the study, 21 factors were included: total score (TS), total number of twopoint shots made (2PSM), total number of twopoint shot attempts (2PSA), total number of threepoint shots made (3PSM), total number of threepoint shot attempts (3PSA), total number of onepoint shots made (1PSM), total number of onepoint shot attempts (1PSA), total number of defensive rebounds (DR), total number of offensive rebounds (OR), total number of rebounds (TNR), total number of assists (A), total number of turnovers (T), assists/turnovers ratio (ATR), total number of steals (S), total number of blocks (B), total number of blocks (AB), total number of fouls made by the team $(\mathrm{CF})$, total number of fouls made by the opponent (RF), EVAL indicator (EVAL), total number of two- and three-point shot attempts ( 2 and $3 \mathrm{PA}$ ), and the total number of one-, two- and three-point shot attempts (All shots A).

Statistical Analysis

Econometrics and modelling prediction were used in the study (Maszczyk et al., 2012; Patil and Rao, 1993). A research pattern with the following structure of variables was employed:

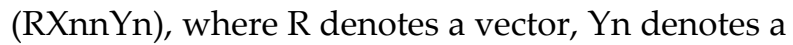
single polytomous dependent variable and Xnn denotes polytomous independent variables in accordance with non-probability sampling. The study followed basic research techniques. Descriptive statistics, a comparison of variable correlations determining the most significant variables for variance, data prediction and mathematic modelling were applied. Additionally, selected statistics were calculated in each of the analysed seasons.

After the structure of the data was analyzed, correlations between the variables describing the study material were investigated. Correlations between all studied variables for all the matches, according to a particular season were presented using Pearson correlation coefficients. Additionally, in order to identify the correlations in detail and establish their statistical significance, the study distinguished 10 data sets according to particular seasons. In all analyses, the level of significance was assumed at $p<0.05$.

Due to a large number of variables with a statistically significant value of the Pearson correlation coefficient (21 variables), a decision was made to reduce the number of variables by optimising the matrix through a factor analysis and determining the $\mathrm{R} 1$ and $\mathrm{R} 0$ vectors.

The starting point for obtaining an optimal combination of variables for the model was calculating the correlation coefficients between the previously determined 21 explanatory variables, according to the following formula:

$$
r_{i j}=\frac{\sum_{t=1}^{n}\left(x_{t i}-\bar{x}_{i}\right)\left(x_{t j}-\bar{x}_{j}\right)}{\sqrt{\sum_{t=1}^{n}\left(x_{t i}-\bar{x}_{i}\right)^{2} \sum_{t=1}^{n}\left(x_{t j}-\bar{x}_{j}\right)^{2}}}(\mathrm{i}, \mathrm{j}=1,2, \ldots, \mathrm{m})
$$

Thus, correlations between the analysed variables were determined and the matrix of correlation coefficients between the analysed explanatory variables was obtained. The R0 vector was also determined. Because a weak correlation between the $X$ explanatory variables and a strong correlation between $\mathrm{X}$ and $\mathrm{Y}$ are favourable for the model, a correlation coefficient analysis was applied to determine the correlation matrix and the correlation vectors and to allow for an optimal choice of predictors, according to the formula:

$$
r_{i}=\frac{\sum_{t=1}^{n}\left(y_{t}-\bar{y}\right)\left(x_{t i}-\bar{x}_{i}\right)}{\sqrt{\sum_{t=1}^{n}\left(y_{t}-\bar{y}\right)^{2} \sum_{t=1}^{n}\left(x_{t i}-\bar{x}_{i}\right)^{2}}}(\mathrm{i}=1,2, \ldots, \mathrm{m})
$$

This helped in determining the optimal variables of the EuroLeague making up the R1 matrix vector for each team, which served as the input vector for constructing the model. 


\section{Results}

The results related to the correlations between all of the studied variables (the values of the obtained correlation coefficients) indicated that a relationship existed in the majority of the analysed cases. The correlations were mostly strong and statistically significant $(p<0.05)$. The correlation between these variables was positive, meaning that a change in the value of one of the variables caused an increase in the value of other variables.

The results of the correlation analysis for all the studied teams are presented in Table 1.

The regression analysis of the dependent variable for all of the 10 studied teams allowed for identification of statistically significant variables that constituted the determinants of performance in the EuroLeague in 2003-2016. Table 2 presents the forward stepwise ridge multiple regression analysis conducted for the ranking of the 10 studied teams.

The analysis helped define the form of the regression function based on the significant independent variables in the regression model. Tau Ceràmica Vitoria is presented as an example of the conducted procedure:

Ranking $(Y)=47.19+0.15$ Reversed fouls +0.78 2PT-made + 1.39 3PT-made + 0.54 1PT-made

The regression analysis showed that for Tau Ceràmica Vitoria, reversed fouls, 2PT-made, 3PT-made and 1PT-made were the most important and statistically significant predictors with regard to their rank in the EuroLeague games in the analysed period. According to the model, all variables had an effect on the number of scored points, while the highest value was obtained for the three-point shots made variable (3PT-made), which increased the score by 1.39 . The variance explained by the independent variables used in the model constituted $98 \%$ of the total variance in the league ranking $(\mathrm{R} 2=0.98)$. The model fitted the data very well $(\mathrm{F}=59.52, p<$ $0.00001)$. The 3PT-made variable $(b=1.39)$ had the highest effect on the ranking in the league, meaning that a higher rank corresponded to, first and foremost, a higher number of three-point shots made (3PT-made). The remaining variables had an equally significant effect on the ranking obtained by Tau Ceràmica Vitoria. However, the total variance of the results in performing the tasks was not explained primarily by the variables marked in the regression model (Reversed fouls, 2PT-made, 3PT-made and 1PT-made), where 3PTmade occurred most frequently.

The verification of the model showed that the signs of the variables located next to the explanatory variables did not contradict the theory of sport, because an increase in the value of any of the variables would result in a higher chance for a better place in the ranking.

The conducted regression analysis (Table 2) indicated that, considering the analysed 10 teams, the following variables were the most often significant predictors which constituted the determinants of sport results in the EuroLeague between 2003-2016: three-point shots made, midrange shots made (2PT-made) and free throws made (1PT-made), the number of two-point shot attempts, the number of three-point shot attempts, the number of fouls, the number of assists and the number of rebounds.

All the analysed variables led to an increase in the number of points scored; however, in seven of the analysed teams (Tau Ceràmica Vitoria, CSKA Moscow, Panathinaikos Athens, Efes Pilsen Istanbul, FC Barcelona, Olympiacos Piraeus and Unicaja Malaga), the highest value was obtained for the three-point shots made variable. In Zalgiris Kaunas and Partizan Belgrade, the highest value was registered for the one-point shot made (1PTmade) variable. Additionally, in one case (Maccabi Tel Aviv), the key variable with the highest value was the number of committed fouls.

\section{Discussion}

The highest number of studies related to factors determining victory in a basketball game has been conducted in the US, thanks undoubtedly to a much higher number of registered game-related statistics compared to the EuroLeague. This results from the vast financial resources, efficient organisation and technological potential of the NBA. The first statistical analyses were conducted, and the directions along with modern research methods were established, in the US. A significant advantage of the NBA is that NBA games are considered to be the best in the world. Publications by Oliver (2004) and Mikołajec et al. (2013) identifying factors determining victory in the NBA are widely known. Oliver (2004) defined four statistics with the highest influence on the game outcome: high 
effectiveness in scoring field goals, the minimal number of turnovers, the maximal number of offensive rebounds and a high number of free throw attempts. The paper by Mikołajec et al.
(2013) is immensely valuable in the context of studies conducted over a long period of time eight consecutive seasons of NBA league games.

\begin{tabular}{|c|c|c|c|c|c|c|c|c|c|c|}
\hline \multicolumn{11}{|c|}{ Pearson's correlation coefficients between the analysed variables in the EuroLeague teams in 2003-2016 } \\
\hline $\begin{array}{l}\text { Team/ } \\
\text { Variable }\end{array}$ & $\begin{array}{l}\mathrm{FC} \\
\text { Barcelona }\end{array}$ & $\begin{array}{l}\text { CSKA } \\
\text { Mosco } \\
\text { w }\end{array}$ & $\begin{array}{l}\text { Efes } \\
\text { Pilsen } \\
\text { Istanbu } \\
1 \\
\end{array}$ & $\begin{array}{l}\text { Maccabi } \\
\text { Tel Aviv }\end{array}$ & $\begin{array}{l}\text { Olympia } \\
\text { cos } \\
\text { Piraeus }\end{array}$ & $\begin{array}{l}\text { Panathina } \\
\text { ikos } \\
\text { Athens }\end{array}$ & $\begin{array}{l}\text { Partizan } \\
\text { Belgrade }\end{array}$ & $\begin{array}{l}\text { Tau } \\
\text { Ceràmic } \\
\text { a Vitoria }\end{array}$ & $\begin{array}{l}\text { Unicaja } \\
\text { Malaga }\end{array}$ & $\begin{array}{l}\text { Zalgiris } \\
\text { Kaunas }\end{array}$ \\
\hline 2PSM & 0.940 & 0.968 & 0.974 & 0.967 & 0.955 & 0.912 & 0.960 & 0.966 & 0.939 & 0.955 \\
\hline 2PSA & 0.935 & 0.950 & 0.955 & 0.955 & 0.971 & 0.872 & 0.945 & 0.959 & 0.916 & 0.924 \\
\hline 3PSM & 0.905 & 0.944 & 0.895 & 0.841 & 0.885 & 0.926 & 0.911 & 0.836 & 0.928 & 0.864 \\
\hline 3PSA & 0.892 & 0.980 & 0.908 & 0.809 & 0.854 & 0.895 & 0.935 & 0.825 & 0.941 & 0.854 \\
\hline 1PSM & - & 0.944 & 0.873 & 0.733 & 0.721 & 0.639 & 0.853 & 0.864 & 0.793 & 0.908 \\
\hline 1PSA & - & 0.946 & 0.901 & 0.824 & 0.819 & 0.683 & 0.841 & 0.862 & 0.794 & 0.869 \\
\hline OF & 0.895 & 0.910 & 0.875 & 0.765 & 0.872 & 0.824 & 0.916 & 0.876 & 0.835 & 0.969 \\
\hline DF & 0.967 & 0.981 & 0.982 & 0.957 & 0.963 & 0.844 & 0.961 & 0.943 & 0.951 & 0.917 \\
\hline TNR & 0.970 & 0.984 & 0.969 & 0.948 & 0.954 & 0.864 & 0.958 & 0.954 & 0.971 & 0.953 \\
\hline A & 0.932 & 0.945 & 0.905 & 0.919 & 0.915 & 0.759 & 0.937 & 0.916 & 0.875 & 0.946 \\
\hline $\mathrm{T}$ & 0.869 & 0.920 & 0.959 & 0.896 & 0.885 & 0.904 & 0.948 & 0.963 & 0.878 & 0.864 \\
\hline S & - & - & - & 0.733 & - & 0.615 & 0.652 & 0.603 & 0.587 & 0.600 \\
\hline ATR & 0.614 & 0.801 & 0.577 & - & 0.732 & - & 0.637 & - & - & 0.581 \\
\hline B & - & 0.865 & 0.773 & 0.715 & 0.848 & 0.692 & 0.815 & 0.706 & - & - \\
\hline $\mathrm{AB}$ & 0.853 & 0.813 & 0.728 & 0.653 & 0.832 & 0.649 & 0.864 & 0.834 & 0.834 & 0.837 \\
\hline $\mathrm{CF}$ & 0.959 & 0.963 & 0.965 & 0.967 & 0.870 & 0.930 & 0.937 & 0.956 & 0.879 & 0.935 \\
\hline $\mathrm{RF}$ & 0.849 & 0.982 & 0.944 & 0.986 & 0.942 & 0.940 & 0.974 & 0.973 & 0.957 & 0.983 \\
\hline 2 and 3 PA & 0.968 & 0.986 & 0.981 & 0.950 & 0.968 & 0.922 & 0.981 & 0.966 & 0.956 & 0.975 \\
\hline $\begin{array}{l}\text { All shots } \\
\text { A }\end{array}$ & 0.979 & 0.991 & 0.993 & 0.990 & 0.980 & 0.981 & 0.993 & 0.992 & 0.989 & 0.988 \\
\hline $\begin{array}{r}\text { 2PSM - } \\
\text { total nu } \\
\text { numb } \\
\text { of de } \\
\text { A - total } \\
\text { of steals } \\
\text { fouls; } \\
\text { and thr }\end{array}$ & $\begin{array}{l}\text { otal num } \\
\text { nber of th } \\
\text { of one-p } \\
\text { ensive rel } \\
\text { number of total } \\
\text { F- total } \\
\text {-point sh }\end{array}$ & $\begin{array}{l}\text { of of tw } \\
\text { nt shot } \\
\text { unds; } \\
\text { ssists; } \\
\text { umber o } \\
\text { attem }\end{array}$ & $\begin{array}{l}\text {-point s } \\
\text { shots m } \\
\text { made; } \\
\text { F - tota } \\
\text { - total } \\
\text { blocks; } \\
\text { freverse } \\
\text { ts; Alls }\end{array}$ & $\begin{array}{l}\text { iots made } \\
\text { de; } 3 P S A \\
\text { PSA - tot } \\
\text { number } \\
\text { zumber o } \\
\text { AB - total } \\
\text { fouls; } E \\
\text { ots } A-t h\end{array}$ & $\begin{array}{l}\text { 2PSA - } \\
\text { - total nu } \\
\text { l number } \\
\text { f offensiv } \\
\text { turnover } \\
\text { number } \\
\text { AL - EV } \\
\text { e total nu }\end{array}$ & $\begin{array}{l}\text { tal numbe } \\
\text { nber of thi } \\
\text { of one-poi } \\
\text { rebounds; } \\
\text { ATR - as } \\
\text { assisted b } \\
\text { L indicat } \\
\text { iber of one }\end{array}$ & $\begin{array}{l}\text { of two-p } \\
\text { t shot att } \\
\text { TNR - to } \\
\text { ists/turn } \\
\text { ocks; CF } \\
r ; 2 \text { and } 3 \\
\text {, two-ar }\end{array}$ & $\begin{array}{l}\text { int shot } \\
\text { hot attem } \\
\text { mpts; D } \\
\text { al numb } \\
\text { vers rati } \\
\text { total nu } \\
\text { PA-tota } \\
\text { d three-p }\end{array}$ & $\begin{array}{l}\text { ttempts } \\
\text { ts; } 1 \text { PS } \\
\text { - total } \\
\text { of rebo } \\
\text { S - toto } \\
\text { iber of c } \\
\text { number } \\
\text { int shot }\end{array}$ & $\begin{array}{l}\text { 3PSM - } \\
1 \text { - total } \\
\text { umber } \\
\text { nds; } \\
\text { number } \\
\text { mmitted } \\
\text { ftwo- } \\
\text { ttempts }\end{array}$ \\
\hline
\end{tabular}


Table 2

Multiple forward stepwise ridge regression analysis conducted for the ranking of the 10 studied teams

\begin{tabular}{|c|c|c|c|c|c|c|c|}
\hline \multicolumn{4}{|c|}{ Tau Ceràmica Vitoria } & \multicolumn{4}{|l|}{ FC Barcelona } \\
\hline $\mathrm{N}=14$ & BETA & $\mathrm{B}$ & $p$ & $\mathrm{~N}=14$ & BETA & B & $p$ \\
\hline Constant & & 47.194 & 0.027 & Constant & & 25.642 & 0.044 \\
\hline Reversed fouls & 0.171 & 0.150 & 0.027 & Reversed fouls & 0.332 & 0.285 & 0.029 \\
\hline 2PT-made & 0.194 & 0.789 & 0.017 & Committed fouls & 0.183 & 0.826 & 0.032 \\
\hline 3PT-made & 0.171 & 1.392 & 0.011 & 2PT-made & 0.254 & 0.629 & 0.039 \\
\hline 1PT-made & 0.136 & 0.541 & 0.023 & 3PT-nade & 0.197 & 1.281 & 0.031 \\
\hline \multicolumn{4}{|l|}{ CSKA Moscow } & \multicolumn{4}{|c|}{ Panathinaikos Athens } \\
\hline $\mathrm{N}=14$ & BETA & $\mathrm{B}$ & $p$ & $\mathrm{~N}=14$ & BETA & B & $p$ \\
\hline Constant & & 37.528 & 0.038 & Constant & & 73.245 & 0.028 \\
\hline Reversed fouls & 0.152 & 0.122 & 0.034 & Reversed fouls & 0.220 & 0.192 & 0.015 \\
\hline 3PT-attempts & 0.134 & 0.554 & 0.037 & 2PT-made & 0.118 & 0.338 & 0.037 \\
\hline 2PT-made & 0.141 & 0.547 & 0.033 & 3PT-made & 0.326 & 2.113 & 0.014 \\
\hline 3PT-made & 0.154 & 1.347 & 0.023 & 1PT-made & 0.134 & 0.869 & 0.028 \\
\hline Committed fouls & 0.121 & 0.516 & 0.035 & 2PT-attempts & 0.080 & 0.643 & 0.030 \\
\hline \multicolumn{4}{|c|}{ Olympiacos Piraeus } & \multicolumn{4}{|c|}{ Maccabi Tel Aviv } \\
\hline $\mathrm{N}=14$ & BETA & B & $p$ & $\mathrm{~N}=14$ & BETA & B & $p$ \\
\hline Constant & & 4.901 & 0.040 & Constant & & 9.317 & 0.035 \\
\hline 2PT-attempts & 0.119 & 0.254 & 0.043 & Reversed fouls & 0.246 & 0.202 & 0.030 \\
\hline Assists & 0.196 & 0.154 & 0.023 & 2PT-made & 0.145 & 0.504 & 0.030 \\
\hline 1PT-made & 0.177 & 1.104 & 0.038 & Assists & 0.199 & 0.787 & 0.014 \\
\hline 3PT-made & 0.264 & 1.841 & 0.034 & Committed fouls & 0.206 & 0.814 & 0.032 \\
\hline 2PT-made & 0.210 & 0.550 & 0.022 & & & & \\
\hline \multicolumn{4}{|c|}{ Efes Pilsen Istanbul } & \multicolumn{4}{|l|}{ Zalgiris Kaunas } \\
\hline $\mathrm{N}=14$ & BETA & $\mathrm{B}$ & $p$ & $\mathrm{~N}=14$ & BETA & B & $p$ \\
\hline Constant & & 27.938 & 0.038 & Constant & & 34.225 & 0.027 \\
\hline Reversed fouls & 0.179 & 0.159 & 0.024 & Reversed fouls & 0.175 & 0.486 & 0.027 \\
\hline Committed fouls & 0.135 & 0.463 & 0.031 & Assists & 0.198 & 0.175 & 0.016 \\
\hline 3PT-made & 0.148 & 1.431 & 0.016 & 1PT-made & 0.148 & 1.208 & 0.014 \\
\hline \multirow[t]{2}{*}{ 2PT-made } & 0.147 & 0.482 & 0.014 & 2PT-made & 0.170 & 0.642 & 0.023 \\
\hline & & & & 3PT-made & 0.267 & 1.010 & 0.045 \\
\hline \multicolumn{4}{|l|}{ Partizan Belgrade } & \multicolumn{4}{|l|}{ Unicaja Malaga } \\
\hline $\mathrm{N}=14$ & BETA & B & $p$ & $\mathrm{~N}=14$ & BETA & B & $p$ \\
\hline Constant & & 10.063 & 0.018 & Constant & & 81.201 & 0.031 \\
\hline Reversed fouls & 0.167 & 0.149 & 0.029 & Rebounds & 0.163 & 0.441 & 0.028 \\
\hline 2PT-made & 0.187 & 0.497 & 0.025 & Reversed fouls & 0.185 & 0.592 & 0.013 \\
\hline 3PT-made & 0.102 & 0.347 & 0.046 & 3PT-made & 0.256 & 2.099 & 0.037 \\
\hline 2PT-attempts & 0.197 & 0.687 & 0.018 & 2PT-made & 0.172 & 1.404 & 0.013 \\
\hline 1PT-made & 0.131 & 1.220 & 0.028 & 1PT-made & 0.148 & 0.552 & 0.026 \\
\hline 3PT-attempts & 0.094 & 0.511 & 0.036 & 2PT-attempts & 0.153 & 0.276 & 0.030 \\
\hline
\end{tabular}


The results of our study indicate that variables that have the highest impact on sport results in the Basketball EuroLeague are: midrange shots made and attempted (2PT-made, 2PTattempts), the number of free throws made (1PTmade), the number of long-distance shots made and attempted (3PT-made, 3PT-attempts), the number of assists and the number of fouls. These variables suggest that offensive factors have the highest effect on victory in EuroLeague games. The advantage in major competitions lies with the teams displaying the highest level of shooting effectiveness. The set of variables with the strongest effect on sport results in EuroLeague games includes the number of fouls. This factor is extremely important because committing a fifth personal foul eliminates the player from further participation in the game, which may have a huge impact on the performance of the entire team. Exceeding the limit of four team fouls in a given quarter allows the opponent to perform free throws, even when the foul was not committed in a shooting situation. This may be a deciding factor, especially in close games, where neither team has a significant advantage in terms of the other elements of play. Mikołajec et al. (2013) conducted a detailed analysis of statistical variables in all teams in the NBA league registered between 2003 and 2011. A comparison between the data obtained in the above mentioned studies and the results presented in this paper indicates that in both cases, the factors related to offence played a very important role and had a significant impact on the final results of the games.

The present study concerned club games at the highest level in Europe. The teams comprised professional players with a high level of technical and tactical skills, who underwent appropriate motor preparation, were able to make optimal decisions during a game, displayed great mental strength and had appropriate somatic characteristics for a given position. Only players who met these criteria are characterised by high performance and a significant impact on the final result. The present study confirmed that factors related to offence, i.e. the number of attempted and made mid-range shots (two-point shots), long-distance shots (three-point shots) and free throws (one-point shots), played a decisive role and had the greatest impact on the results of the
EuroLeague competition considered in this study. An additional factor was the number of assists, which is a clear indicator of the quality of teamwork and of how much the team uses twoand three-player solutions. The dominance of offensive elements partly results from the fact that the number of registered offensive variables is considerably higher when compared to the defensive variables. In addition, the number of scored points is strongly correlated with the number of attempted shots and shooting effectiveness. Winning by performing few and low percentage shots seems very difficult. It seems only possible if the team's defence is excellent, what limits the opposing team's offensive effectiveness. If the defensive play in both teams is at a similar level, the team with greater offensive efficiency always wins. The presence of both mid-range shots and longdistance shots in the combination of variables with the highest effect on the game outcome in the EuroLeague indicates the importance of balanced positional effectiveness. This results from the fact that two-point shots are usually the domain of tall players at the centre (5) and power forward (4) positions. Conversely, long-distance shots are the domain of the perimeter players at shooting guard (2), small forward (3), and point guard (1) positions. The threat created by tall players within a restricted area and the necessity for teamguarding the centre player (double-teaming) very often allows for wide-open distance shots to be made. A precise execution of the free throws after fouls committed by defensive players on players finishing their actions within the restricted area is not less significant. This is particularly important in close games, where difference in the score amounts to just few points. Hence, the efficiency of a free throw can decide between a victory and a loss. It should also be noted that in players in Position 1 (point guards), the number of assists is a variable that significantly affects the value of these players during a game. It confirms the player's creativity and ability to create opportunities for scoring points for other players on the team. These data have been confirmed through the evaluation of the best teams. Building such a team starts with selecting the right players for Positions 1, 2/3 and 5. It should also be mentioned that modern high-level basketball requires the players to have good versatility (the 
ability to perform numerous tasks at different positions). This particularly applies to the player at Position 4 (power forward).

A study by Szwarc et al. (2013) confirms that power forwards and centres are the most active and efficient players in scoring two-point shots. This is characteristic of the players at these positions, because they are the ones tasked with scoring in the restricted area (centres) and via mid-range shots (power forwards). Scoring threepoint shots is the main offensive task given to perimeter players; that is, to point guards (Position 1), shooting guards (Position 2) and small forwards (Position 3). The results of our study confirm the high activeness of the players at these positions. However, the observed high efficiency of power forwards in scoring via threepoint shots may come as a surprise. This observation is probably related to new trends in the manner of organising plays in modern basketball (Oliver, 2004), and the changing somatic and fitness profile of the players (Gómez et al., 2017; Petreanu and Petreanu, 2016). The versatility of players and their ability to play at each position, as observed in recent years, seems particularly important. This phenomenon seems to be further substantiated because many changes in basketball rules were introduced during the analysed period, making this sport even more dynamic and spectacular (Pluta et al., 2015). Shortening the offensive actions to $24 \mathrm{~s}$ as well as the necessity to advance the ball over the half court line within $8 \mathrm{~s}$, have certainly contributed to making the duration of a single play shorter. As a result, more offensive actions are carried out and a higher number of shots are taken during the game.

A study by Pluta et al. (2015) showed a correlation between the dynamics of scoring in basketball and the changes in the rules. They investigated the effect of the modified rules on scoring during 38 consecutive Men's European Basketball Championships between 1938-2013. It was observed that rule changes did not always affect the victory in a basketball game during the European Championships; however, they did lead to a significant increase in the scores. Over the years, the following changes in the rules had the greatest effect on the pace of the game and on the dynamics of scoring (e.g. the three second rule, the introduction of a time limit for carrying out an offensive action, the introduction of three-point shots).

The division of the game into four quarters, shortening the amount of time allowed for carrying out offensive action from 30 to $24 \mathrm{~s}$, and reducing the time limit for advancing the ball to the frontcourt from 10 to $8 \mathrm{~s}$ have resulted in significantly faster paced games. These rule changes are most advantageous for dynamic and versatile players, due to a more intensive gameplay. A dynamic transition from defence to offence allows players to outnumber their opponents during fast breaks. The skill of playing one-on-one and a higher level of physical fitness and technique become immensely important. Furthermore, a quick transition from defence to offence often ends in a three-point shot. Montero et al. (2013) revealed that increasing the distance between the three-point line and the basket to 6.75 $\mathrm{m}$ in 2010 resulted in a higher number of accurate three-point shots. In their study, 290 games of the Spanish ACB Liga in the 2009-2010 season were analysed. Similarly, Štrumbelj et al. (2013) revealed an increase in the number of three- and two-point shot attempts in EuroLeague games during the same period of time. The same trend of change was registered in the NBA and NCAA leagues after moving the three-point line further back (Magel an Unruh, 2013; Štrumbelj et al., 2013).

\section{Conclusions}

In summary, this study provided team game-related statistics that determined sport results in the Basketball EuroLeague between 2003 and 2016. It was found that the main factors that influenced the game outcome at the elite level were more related to offense than defence (reversed fouls, 2 PT made, 3 PT made, 1 PT made). The results of this study may enhance the short- and long-term training process. In practical terms these findings may also help team managers to select appropriate players to their professional teams. 


\section{References}

Çene E. What is the difference between a winning and a losing team: insights from Euroleague basketball. Int J of Perf Anal Spor, 2018; 18(1): 55-68 DOI: 10.1080/24748668.2018.1446234

Côté J, Gilbert W. An Integrative Definition of Coaching Effectiveness and Expertise. Int J Sports Sci Coach, 2009: 4(3): 307-323 https://doi.org/10.1260/174795409789623892

Csataljay G, O'Donoghue P, Hughes M, Dancs H. Performance indicators that distinguish winning and losing teams in basketball. Int J of Perf Anal Spor, 2009; 9(1): 60-66

Dehesa R, Vaquera A, Gómez-Ruano MÁ, Gonçalves B, Mateus N, Sampaio J. Key performance indicators in NBA players' performance profiles. Kinesiology, 2019; 51: 92-101 https://doi.org/10.26582/k.51.1.9

Doğan I, Ersöz Y. The Important Game-Related Statistics for Qualifying Next Rounds in Euroleague. Montenegrin Journal of Sports Science and Medicine, 2019; 8(1): 43-50

Esteves PT, Mikolajec K, Schelling X, Sampaio J. Basketball performance is affected by the schedule congestion: NBA back-to-backs under the microscope. Eur J Sport Sci, 2020; 14(1): 1-10

Fernandez J, Camerino O, Anguera MT, Jonsson GK. Identifying and analyzing the construction and effectiveness of offensive plays in basketball by using systematic observation. Behav Res Methods, 2009; 41(3): 719-730

Gomes JH, Mendes RR, Zanetti MC, Santos-Leite G, Ferreira AJ. Relationship between physical fitness and game-related statistics in elite professional basketball players: Regular season vs. playoffs. Motriz Revista de Educação Física, 2017; 23(2): 1-6

Gómez MA, Ibáñez SJ, Parejo I, Furley P. The use of classification and regression tree when classifying winning and losing basketball teams. Kinesiology, 2017; 49(1): 47-56

Gryko K, Mikołajec K, Marszałek J, Adamczyk JG, Molik B, Waśkiewicz Z, Nikolaidis P, Knechtle B. How did basketball teams win EuroBasket 2015? A non-standard analysis of performance based on passes, dribbling and turnovers. Int J of Perf Anal Spor, 2020; 20(3): 339-356

Gryko K, Mikołajec K, Maszczyk A, Cao R, Adamczyk JG. Structural analysis of shooting performance in elite basketball players during FIBA EuroBasket 2015. Int J of Perf Anal Spor, 2018; 18(2): 380-392 DOI: $10.1080 / 24748668.2018 .1479923$

Hughes MD, Bartlett R. M. The use of performance indicators in performance analysis. J Sports Sci, 2002; 20(10): 739-754

Ibáñez SJ, Garcia J, Feu S, Lorenzo A, Sampaio J. Effects of consecutive basketball games on the game-related statistics that discriminate winner and losing teams. J Sport Sci Med, 2009; 8(3): 458-462

Ibáñez SJ, Sampaio J, Feu S, Lorenzo A, Gómez MA, Ortega E. Basketball game-related statistics that discriminate between teams' season-long success. Eur J Sport Sci, 2008; 8(6): 369-372

Keele L, Kelly NJ. Dynamic models for dynamic theories: The ins and outs of lagged dependent variables. Polit Anal, 2006; 14(2): 186-205

Lago-Peñas C, Lago-Ballesteros J, Dellal A, Gómez MA. Game-related statistics that discriminated winning, drawing and losing teams from the Spanish soccer league. J Sport Sci Med, 2010; 9(2): 288-293

Lorenzo A, Gómez MA, Ortega E, Ibáñez S, Sampaio J. Game related statistics which discriminate between winning and losing under-16 male basketball games. J Sport Sci Med, 2010; 9(4): 664-668

Magel R, Unruh S. Determining factors influencing the outcome of college basketball games. Open Journal of Statistics, 2013; 3(4): 225-230

Mandić R, Jakovljević S, Erčulj F, Štrumbelj E. Trends in NBA and Euroleague basketball: Analysis and comparison of statistical data from 2000 to 2017. PLoS One, 2019; 14(10):e0223524 doi:10.1371/journal.pone.0223524

Marmarions C, Apostolidis N, Kostopoulos N, Apostolidis A. Efficacy of the 'pick and roll' offense in top level European basketball teams. J Hum Kinet, 2016; 51: 121-129

Maszczyk A, Roczniok R, Czuba M, Zając A, Waśkiewicz Z, Mikołajec K, Stanula A. Application of regression and neural models to predict competitive swimming performance. Percept Mot Skills, 2012; 114(2): 610-624

Mikołajec K, Maszczyk A, Zając T. Game indicators determining sports performance in the NBA. J Hum Kinet, 2013; 37(1): 145-151 
Montero A, Vila H, Longarela B. Influence of changing the distance of the 3-point line in basketball. Rev de Psicol del Deporte, 2013; 22(1): 245-248

Oliver D. Basketball on paper: Rules and tolls for performance analysis. Washington D.C., Potomac Books; 2004

Ortega E, Cárdenas D, Sainz de Baranda P, Palao JM. Differences between winning and losing teams in youth basketball games (14-16 years old). Int J Appl Sports Sci, 2006; 2(18): 1-11

Özmen MU. Marginal contribution of game statistics to probability of winning at different levels of competition in basketball: Evidence from the Euroleague. Int J Sports Sci Coach, 2016; 11(1): 98-107 doi:10.1177/1747954115624828

Parejo I, García A, Antúnez A, Ibáñez SJ. Differences in performance indicators among winners and losers of group A of the Spanish basketball amateur league (EBA). Rev de Psicol del Deporte, 2013; 22(1): 257261

Patil GP, Rao CR. (Eds.). Multivariate environmental statistics. Handbook of Statistics, 1993; 12: 79-83.

Paulauskas R, Masiulis N, Vaquera A, Figueira B, Sampaio J. Basketball Game-Related Statistics that Discriminate Between European Players Competing in the NBA and In the Euroleague. J Hum Kinet, 2018; 65: 225-233 doi:10.2478/hukin-2018-0030

Petreanu AG, Petreanu M. Study regarding team statistics at the last three Men's Basketball World Championships. Timişoara Physical Education and Rehabilitation Journal, 2016; 9(17): 29-35

Pluta B, Andrzejewski M, Lira J. The effects of rule changes on basketball game results in the Men's European Basketball Championships. Hum Mov, 2015; 15(4): 204-208

Robertson S, Gupta R, McIntosh S. A method to assess the influence of individual player performance distribution on match outcome in team sports. J Sports Sci, 2016; 34(19): 1-8

Sampaio J, Janeira M. Statistical analyses of basketball team performance: understanding teams' wins and losses according to a different index of ball possessions. Int J of Perf Anal Spor, 2003; 3(1): 40-49

Sampaio J, Lago C, Drinkwater EJ. Explanations for the United States of America's dominance in basketball at the Beijing Olympic Games. J Sports Sci, 2010; 28(2): 147-152

Sampaio J, Leser R, Baca A, Calleja-Gonzalez J, Coutinho D, Gonçalves B, Leite N. Defensive pressure affects basketball technical actions but not the time - motion variables. J Sport Health Sci, 2016; 5(3): 375-380

Štrumbelj E, Vračar P, Robnik-Šikonja M, Dežman B, Erčulj F. A decade of Euroleague basketball: An analysis of trends and recent rule change effects. J Hum Kinet, 2013; 38(1): 183-189

Szwarc A, Lekner I, Lipińska P. The efficiency of action of the top level basketball players with regard to the player position. Rozprawy Naukowe, AWF Wrocław, 2013, 42:44-61.

\section{Corresponding author:}

\section{Karol Gryko, Ph.D}

Józef Piłsudski University of Physical Education in Warsaw

Faculty of Physical Education, Department of Sport Games

Marymoncka 34

Warszawa 00-968, Poland

Phone: + 504148 465, + 48228340431 ex. 577

E-mail: karol.gryko@awf.edu.pl 